\title{
A test of the Becker-Tomes model of human capital transmission using microdata on four generations*
}

by

\author{
Mikael Lindahl, Mårten Palme, Sofia Sandgren Massih and Anna Sjögren ${ }^{\S}$
}

January $16^{\text {th }}, 2013$

\begin{abstract}
We estimate the well-known Becker-Tomes (1986) model of intergenerational transmission of human capital. A Swedish data set which links individual measures on educational attainments of four generations, enables us to use great grandparents' education as an instrumental variable. This approach was suggested already in BeckerTomes (1986) but, because of the lack of data, never implemented. The identifying assumption, which holds within the Becker-Tomes framework, is that great grandparents' education is unrelated to great grandchild's education, conditional on the education of the parent and grandparent. We test the prediction that the structural parameter for grandparents' education enters with a negative sign in an intergenerational regression model where the education of a child is linearly related to the education of the parent and the education of the grandparent. We fail to find empirical support for the model's predictions.
\end{abstract}

Keywords: The Becker-Tomes model, Human capital transmission, Multigenerational effects

JEL-codes: D31; J62

\footnotetext{
* We thank Anders Björklund, Susan Dynarski, Peter Fredriksson, Caroline Hall and Björn Öckert as well as seminar participants at Uppsala, SOFI (Stockholm University), Trondheim, the CESIfo 2011 meeting in Munich, the 2011 Nordic Summer Institute in Labor Economics at the Faroe Islands and the Conference on the Economics of the Family (INED) in Paris 2011 for valuable comments on previous drafts and Eskil Forsell, Erika Karlenius and Arvid Olovsson for excellent research assistance. Special thanks to Adrian Adermon for help with the data construction and programming.

Mikael Lindahl is a Royal Swedish Academy of Sciences Research Fellow supported by a grant from the Torsten and Ragnar Söderberg Foundation, the Scientific Council of Sweden and the European Research Council [ERC starting grant 241161]. Mårten Palme gratefully acknowledges financial support from the Swedish Council of Social Research. Swedbank has provided financial support for the construction of the dataset.

${ }^{\S}$ Mikael Lindahl: Department of Economics, Uppsala University, SE-751 20 Uppsala, Sweden, CESifo, IFAU, IZA and UCLS, E-mail: Mikael.Lindahl@nek.uu.se; Mårten Palme: Department of Economics, Stockholm University, SE-106 91 Stockholm, Sweden and IZA, E-mail: Marten.Palme@ne.su.se; Sofia Sandgren: Department of Economics, Uppsala University, SE-751 20 Uppsala, Sweden; and Anna Sjögren: IFAU, Box 513, SE-751 20 Uppsala, Sweden, UCLS, Uppsala, and SOFI Stockholm University, E-mail: Anna.Sjogren@ifau.uu.se.
} 


\section{Introduction}

The association between different SES indicators across generations is probably one of the most well established empirical regularities in the social sciences. In economics there are two main theoretical models rationalizing this result. First, a model originally formulated by Sir Francis Galton and developed by e.g. Goldberger (1989) suggesting a "mechanical" transmission of different endowments that constitute socio-economic status. Second, the Becker and Tomes $(1979,1986)$ model which is built on economic or "optimizing" behavior of parents investing in the future success of their children." The Becker-Tomes model has provided a theoretical foundation for the upsurge of intergenerational estimations in the last two decades (see Solon, 1999, and Black and Devereux, 2010, for reviews).

A key prediction of the simple Becker-Tomes model (1986) is that the structural parameter for grandparents' education enters with a negative sign in an intergenerational regression model where the education of a child is linearly related to the education of the parent and the education of the grandparent. However, a test of this prediction is complicated by the fact that in the Becker-Tomes model, the education of the parent is necessarily correlated with the error term in this $\operatorname{AR}(2)$ model of intergenerational education transmission. However, as suggested already in BeckerTomes (1986), if one has information on four generations of educational data, one can purge this endogeniety by using the education of the great grandparent as an instrument for the education of the parent.

In this paper we are able to apply this approach since we have access to an exceptional Swedish data set containing measures of educational attainments for four generations. The data set is based on a survey of all third graders in Sweden's third largest city, Malmö, and its suburbs, in 1938. The first generation, i.e. the parents of the surveyed third graders, was, on average, born in the late nineteenth century and the fourth generation typically completed their education in the early twenty-first century. Altogether there are 901 complete families, i.e., families where education data are available on at least one individual in each of four consecutive generations.

\footnotetext{
${ }^{1}$ See Mulligan (1999) and Piketty (2000) for discussions about the contribution of the Becker-Tomes model in relation to more mechanical models of intergenerational transmission. See also Goldberger (1989) for an opposing view.
} 
When we estimate the AR(2) model using OLS, we find a positive and significant association between the education of the children and the education of the grandparents, conditional on parent's education. We then turn to instrumental variable estimation, where we use the educational attainment of the great grandparent generation as an instrumental variable. The identifying assumption in these instrumental variable estimations is that there is no direct effect of great-grandparents on the outcome of the child, conditional on the grandparental and parental outcomes. This assumption is credible since it is rare for great-grandparents to directly meet and interact with their great- grandchildren. As a robustness check we re-run the estimation on the subsample where children were born after the great grandparents have died. Our results suggest that we cannot reject a zero effect for grandparents' education, i.e., we do not find support for the key prediction of the Becker-Tomes model.

The paper proceeds as follows. In Section 2 we introduce the data set, discuss the construction of variables and provide some descriptive statistics of the variables used in this study. In Section 3 we outline the simple Becker-Tomes model of intergenerational transmission and test it using data on education spanning four generations. Section 4 concludes.

\section{Data and descriptive statistics}

The data set we use consists of information on individuals from four generations of the same families. ${ }^{2}$ All pupils attending third grade (normally at age 10) in any school in the Malmö metropolitan area $(n=1,542)$ were part of the original survey and constitute the index generation, which is the second generation included in the data set. The original purpose was to analyze the correlation between social environment and cognitive ability. Hence, a host of family background information was collected, including information on father's education. Over the years, the Malmö Study has been extended with information from both several rounds of follow-up surveys and register data. ${ }^{3}$

\footnotetext{
${ }^{2}$ The data set originally stems from the so called Malmö Study, a survey initiated in 1938 by a team of Swedish educational researchers. The material was originally collected by Siver Hallgren and developed by Torsten Husén.

${ }^{3}$ In 1993, 38\% of the third and fourth generations still lived in Malmö, an additional 31\% lived elsewhere in the county of Skåne, which is where Malmö is situated, $8 \%$ lived in the county of Stockholm, and the rest were quite evenly spread out in the rest of Sweden.
} 
We have extended the data in several ways. We have added parish-register information on date of birth and death of the parents of the index generation. These parents constitute the first generation and were born between 1865 and 1912. We have also added register information on the second generation's children and grandchildren, as well as information on the spouses of the index generation, i.e., the second parent of these children and of the grandchildren. The resulting data set consists of information on four generations of the same families. The average birth year of the first generation is 1898. The second generation, i.e. the index generation, is on average born in 1928; the third generation, the children of the index generation, in 1956; and, finally, the fourth generation, the grandchildren of the index generation, in 1985. In Lindahl et al (2012) we provide a more detailed account of this data set.

\subsection{Data on educational attainment}

The measure of educational attainments for the first generation was constructed by educational scientists and based on occupational classification of fathers from a survey in 1938. For the second to fourth generations, we have obtained data on educational attainments from the national education register. We mainly use data from 1985 for the second generation and from 2009 for the third and fourth generations. We transform the educational level measure for all generations into years of schooling based on the required number of years that has to be completed for each level. ${ }^{4}$ In order to avoid the problem that some children in the youngest generation may still have been in school at the time of data collection, we restrict the analysis of years of education to individuals who were at least 25 years of age in 2009, hence excluding those born after 1984.

In order to further increase the sample size for the analysis of education transmission, we also construct a measure of whether or not an individual has completed an academic track in high school. This is a strong predictor of whether or not the individual

\footnotetext{
${ }^{4}$ With detailed information on completed level of education, we construct years of schooling as follows: 7 for (old) primary school, 9 for (new) compulsory schooling, 9.5 for (old) post-primary school (realskola), 11 for short high school, 12 for long high school, 14 for short university, 15.5 for long university, and 19 for a PhD. For those few individuals in the second generation where registry information for 1985 is missing, we use survey information from 1964. The education information from 1964 is in 6 levels, and probably of lower quality than for 1985 or 2009. The conversion is done by imputing years of schooling by regressing the years of schooling variable in 1985 on indicators for 1964 using all individuals for whom educational information is available in both years. For individuals in the third generation with missing education data, we instead draw on registry information from 2005 and 1985 .
} 
continues on to higher education. We are then able to include children born until 1990. This increases the sample by about 35 percent.

\subsection{Descriptive statistics}

We have information on educational attainments for 901 complete families, i.e., with data available on at least one individual in each generation, for four consecutive generations. ${ }^{5}$ We only use individuals who are biologically related across the four generations. The main reason for attrition of families is that the individual has no children. There are, however, some individuals with missing information on education.

Table 1 reports descriptive statistics by generation and gender for the samples used in this study. We show statistics corresponding to the individuals in our estimation sample for education (four generations separated by gender). The first column shows means and standard deviations for the fathers of the children in the index generation (generation 2). These 905 fathers were on average born in 1896 and had 7.3 years of schooling. The next two columns show descriptive statistics for those in the index generation (first interviewed in 1938 and typically born in 1928) as well as mothers and fathers of the children in the third generation. For this second generation, typically born in 1928, there are 470 men who acquired 10.2 years of schooling and 435 women who acquired 9.5 years, on average.

The last two columns show descriptive statistics for the descendants of the three earlier generations who are old enough to be included in the regressions: i.e. 25 years of age in 2009 for education estimations; and, finally, 19 years of age for the academic high-school track regressions.

\footnotetext{
${ }^{5}$ We have 901 complete families with four generations when we include fourth generation children born until 1990. For this sample, the education measure used for the fourth generation is academic high-school track. In order to obtain a meaningful measure of years of education for the fourth generation, we restrict the analysis to children born before 1986, resulting in 673 complete families.
} 
Table 1: Descriptive statistics

\begin{tabular}{|c|c|c|c|c|c|c|c|}
\hline \multirow[b]{2}{*}{ Variable } & \multirow{2}{*}{$\begin{array}{c}\begin{array}{c}\text { Generation } 1 \\
\text { (great- } \\
\text { grandparents) }\end{array} \\
\text { Great- } \\
\text { grandfather } \\
\text { (1) }\end{array}$} & \multicolumn{2}{|c|}{$\begin{array}{c}\text { Generation } 2 \\
\text { (grandparents) }\end{array}$} & \multicolumn{2}{|c|}{$\begin{array}{l}\text { Generation } 3 \\
\text { (parents) }\end{array}$} & \multicolumn{2}{|c|}{$\begin{array}{l}\text { Generation } 4 \\
\text { (children) }\end{array}$} \\
\hline & & $\begin{array}{c}\text { Grandmothe } \\
r \\
(3) \\
\end{array}$ & $\begin{array}{c}\text { Grandfather } \\
\text { (4) }\end{array}$ & $\begin{array}{l}\text { Mother } \\
\text { (5) }\end{array}$ & $\begin{array}{c}\text { Father } \\
\text { (6) }\end{array}$ & $\begin{array}{c}\text { Daughter } \\
\text { (7) }\end{array}$ & $\begin{array}{l}\text { Son } \\
(8)\end{array}$ \\
\hline \multirow{3}{*}{$\begin{array}{l}\text { Years of } \\
\text { schooling }\end{array}$} & 7.30 & 9.53 & 10.15 & 12.05 & 12.11 & 12.95 & 12.42 \\
\hline & $(1.60)$ & $(2.67)$ & (2.96) & $(2.47)$ & $(2.59)$ & (1.98) & (2.13) \\
\hline & {$[5,14]$} & {$[7,19]$} & {$[7,20]$} & {$[7,20]$} & {$[7,20]$} & {$[7,20]$} & {$[7,20]$} \\
\hline \multirow{2}{*}{$\begin{array}{l}\text { Academic HS } \\
\text { track }\end{array}$} & & & & & & 0.55 & 0.44 \\
\hline & & & & & & $\begin{array}{c}(0.50) \\
{[0,1]}\end{array}$ & $\begin{array}{c}(0.50) \\
{[0,1]}\end{array}$ \\
\hline Year of birth & $\begin{array}{c}1896.12 \\
(7.20) \\
{[1859,1910]}\end{array}$ & $\begin{array}{c}1927.91 \\
(0.40) \\
{[1925,1930]}\end{array}$ & $\begin{array}{c}1927.87 \\
(0.40) \\
{[1926,1929]}\end{array}$ & $\begin{array}{c}1954.67 \\
(4.90) \\
{[1944,1970]}\end{array}$ & $\begin{array}{c}1954.53 \\
(4.46) \\
{[1943,1969]}\end{array}$ & $\begin{array}{c}1981.45 \\
(6.30) \\
{[1962,1990]}\end{array}$ & $\begin{array}{c}1981.49 \\
(6.35) \\
{[1962,1990]}\end{array}$ \\
\hline $\begin{array}{l}\text { Number of } \\
\text { obs. }\end{array}$ & 905 & 435 & 470 & 831 & 722 & 1,451 & 1,548 \\
\hline
\end{tabular}

Notes: The first figure in each cell is the mean of the variable. The figure in parenthesis is the standard deviation and the figures in square breackets are minimum and maximum values, respectively. The education statistics are calculated for the observations used in Table 2 (column 1) and Table 3 (columns 1-2). The statistics for year of schooling for generation 4 are calculated for those born before 1985 (887 daughters and 936 sons).

\section{Estimating the Becker-Tomes model of intergenerational transmission of human capital}

\subsection{The model and its predictions}

From the Becker-Tomes (BT) model of intergenerational human capital transmission it follows that the earnings of a child are positively related to the earnings of the parent, the endowment of the child and an error term referred to as "market luck". The positive impact of parental earnings on the earnings of the child can be derived from utility maximization where parents optimize between own consumption and investment in 
children's human capital (as in Becker and Tomes, 1979) or because of the existence of borrowing constraints (as in Becker and Tomes, 1986). ${ }^{6}$

As in Behrman and Taubman (1985), we here explicitly express the BT-model in terms of education instead of earnings/income. ${ }^{7}$ This results in a link between schooling for children and parent specified as:

$$
s_{t}=\alpha+\beta s_{t-1}+\rho e_{t}+u_{t}
$$

i.e., education $(s)$ of the child-generation $t$ is a linear additive function of education in the parental generation $s_{t-1}$, unobserved endowment or ability $(e)$ and an error term $(u)$ capturing any exogenous shocks affecting $s_{t}$. By construction, $E\left[u_{t} \mid s_{t-1}, e_{t}\right]=0$ so that $u_{t}$ is uncorrelated with both $e_{t}$ and $s_{t-1}$. The intergenerational educational effect $\beta$ is expected to be positive because of positive returns to parental investments in human capital.

BT also postulates that transmission of endowments from one generation to the next can be described as an $\mathrm{AR}(1)$ process:

$$
e_{t}=\mu+\lambda e_{t-1}+v_{t}
$$

where, by construction, $E\left[v_{t} \mid e_{t-1}\right]=0$, so that the random error $v_{t}$ is uncorrelated with $e_{t-1}$. Note that endowments include not only genetically determined ability, but also culture and behavioral factors. ${ }^{8}$ In fact, endowments include all factors transmitted from parent to child, as long as these endowments impact child's education (conditional on parent's education).

\footnotetext{
${ }^{6}$ See also Solon (1999) for an alternative derivation.

${ }^{7}$ In a simple model of human capital transmission between parent and child we get somewhat different interpretation of $\beta$, depending of whether we model the relationship in terms of education or income. For income, we have that $\beta$ is the product of the child's return to education and parental return on investment in child's education, whereas for education, we have that $\beta$ is the product of parental return on investment in child's education and parent's return to own education. See Holmlund, Lindahl and Plug, 2008, Plug and Vijverberg, 2005, and Sauder, 2006 for examples where $\beta$ has a structural interpretation in terms of education.

${ }^{8}$ Plug and Vijverberg, 2003 attempts to decompose the endowment transmission, $\lambda$, into genetic and nongenetic parts using data on adoptees and their rearing parents. They find that $50-70 \%$ is genetically transmitted.
} 
Note that the BT model as expressed in equations (1) and (2), does not allow for a direct effect of grandparents' education on the education of grandchildren. Grandparents affect the education of grandchildren only indirectly through the inheritance of endowments. In the presence of credit constraints, grandparents also influence grandchildren's education through their investment in the human capital of the parent generation.

An immediate implication of this model is that a bivariate regression of children's education on parent's education leads to an upward bias in the estimation of $\beta$, since those with higher endowment also have higher education. This implication has received empirical support in several studies (see e.g. Holmlund, Lindahl and Plug, 2011). ${ }^{9}$ To arrive at a model with observable variables, Becker-Tomes suggested that we use the expressions in (1) and (2) to obtain: ${ }^{10}$

$$
s_{t}=\alpha^{\prime}+(\beta+\lambda) s_{t-1}-\beta \lambda s_{t-2}+\rho v_{t}+u_{t}-\lambda u_{t-1} \text {. }
$$

The BT model, hence, implies a negative effect of grandparents' education on children's education conditional on parent's education. The intuition for this negative coefficient on $s_{t-2}$, is that high grandparental education, $s_{t-2}$, implies low parental endowment, $e_{t-1}$, for a given level of parental education, $s_{t-1}$. From equation (3) it is also clear that an OLS regression of children's outcome on parent's and grandparent's outcome generates biased estimates: the coefficient on parent's education, $\beta+\lambda$, is estimated with a negative bias and the coefficient on grandparents education, $-\beta \lambda$, is estimated with a positive bias. The reason is that a first-order lagged version of equation (1) implies that the covariance between parental schooling and parental market luck is positive, i.e. $\operatorname{cov}\left(s_{t-1}, u_{t-1}\right)>0$. To get consistent estimates we therefore need an alternative approach.

\footnotetext{
${ }^{9}$ There is also some evidence that a bivariate regression of children's income on parent's income gives an overestimate of the causal intergenerational income effect (see Björklund, Lindahl, and Plug, 2006, and Lefgren, Lindquist and Sims, 2011)

${ }^{10}$ Equation (3) follows from equation (1) and (2) simply because the latter two equations constitute an $\mathrm{AR}(1)$ model with an autocorrelated error term, which can be rewritten as an AR(2) model, where the coefficient on the first lagged variable will be positive and the coefficient on the second lagged variable will be negative. Also, note that for the constant in equation (3) we have that $\alpha^{\prime}=\alpha(1-\lambda)+\rho \mu$.
} 
The first attempt to estimate equation (3), addressing the endogeneity problem of parental education, is provided in Behrman and Taubman (1985). Using a sample of descendents of twins, they first estimate equation (3) with OLS and find that grandparent's education is insignificantly related to grandchildren's education. Their IV-estimation, using the education of the grandfather's twin brother as an instrument for father's education, yields a significantly positive estimate of the effect of grandparent's education on child outcomes. As a result, they conclude that they cannot find support for the prediction of the BT model. A limitation of their study is, however, that the sample is only generalizable to a rather restrictive population consisting of the offspring of twins, in particular the offspring of white male twins who served in the military during WWII. Furthermore, although novel and creative, the IV approach makes the questionable assumption that the education of a twin has no impact on educational attainment of the co-twin's child. This would not hold if the twins, who are often close to one another as adults, influence each other's children.

An alternative approach is used in a study by Sauder (2006) on U.K. data. He finds positive impact of grandparent's education using OLS, but no effect using IV. The IV approach exploits i) two distinct schooling reforms that took place in 1947 and 1973 in the U.K. and ii) mothers' birth order as instruments for parent's and grandparent's education. However, both instruments are problematic. First, it is difficult to separate cohort effects from reform effects when a reform, as was the case here, is introduced simultaneously in the whole country. Second, birth-order may affect post-education outcomes also through other channels than educational attainment, as is found in Black, Devereux and Salvanes (2005a).

Our approach, suggested already by Becker and Tomes, is to use great-grandparents' education as an instrument for parents' education, in a regression of children's education on parents' and grandparents' education. The identifying assumption is that great-grandparents' education has no impact on great-grandchildren's education, over and above the impact through parents' and grandparents' education. This assumption necessarily holds in the simple Becker-Tomes model as expressed above. Since we have access to four generations of data for education, we can implement this strategy here. 
In what way does a test of a negative coefficient on grandparents education in (3) constitute a test of the Becker-Tomes model? What does it mean if we find no support for this key prediction of the Becker-Tomes model? Two issues are important here.

First, we need to specify an alternative to the Becker-Tomes model where the exclusion restriction still can hold. This will be the case in a model where $\beta=0$, but for instance not in a model where we generalize the Becker-Tomes model to incorporate grandparents education directly in equation (1). ${ }^{11}$ Hence, our test is to see if we can reject a special case of the Becker-Tomes model (as outlined in equations (1) and (2)). This model would be more in line with a meritocratic model of intergenerational transmission, where success of the child generation depends on ability, but not on investments made by parents. Even though we are not able to investigate empirically the separate mechanisms determining $\beta$, failing to find support for the Becker-Tomes model would be in line with the interpretation that credit constraints are of little importance for children born in Sweden during the 1970s and 1980s. ${ }^{12}$

Second, we need the exclusion restriction to hold. The identifying assumption in the instrumental variable estimations is that there is no direct effect of great-grandparents on the outcome of the child, conditional on the grandparental and parental outcomes. Is this likely to be the case? The credibility of this assumption hinges on how likely it is for great-grandparents to directly meet and interact with their great- grandchildren. In order to gauge the importance of this channel, we perform instrumental variable

\footnotetext{
${ }^{11}$ The Becker-Tomes model as expressed in equation (1) and (2) can be extended in a number of ways. One natural extension is to allow for a direct influence of grandparents on grandchildren (for instance because of investments in human capital being made both by parents and grandparents) and thus add grandparents' outcome, i.e. the term $\theta s_{t-2}$, to equation (1). If this is done, one can derive a revised equation (3), where the coefficient on $s_{t-2}$ changes from $-\beta \lambda$ to $\theta-\beta \lambda$. This means that we would see a positive coefficient estimate for grandparent's outcome, in a regression of child's outcome on parents and grandparent's outcome, as long as $\theta$ is large enough. The OLS and IV estimates in Tables 2 and 3 are more compatible with this modified model, than with the simplest version of the Becker-Tomes model. In this revised regression model (3) we would also have great grandparents outcome as an added right-hand side variable (whose coefficient would be equal to $-\theta \lambda$ ). Other simple extensions to the modeling framework in equations (1) and (2) are of course also possible. For example we could add $e_{t-2}$ to equation (2), hence allowing for the endowment or cultural transmission to children to come from both parents and grandparents. This is more likely to give a positive coefficient on $s_{t-2}$ the higher is the endowment transmission from grandparents relative the endowment transmission from the parents, and the lower is $\beta$ in equation (1). Another example is to add an interaction term $s_{t-1} e_{t}$ to equation (1), which would mean that endowment or culture is transmitted differently across the income distribution, perhaps because of nature-nurture interactions.

${ }^{12}$ Mulligan (1999) discusses and tests features of the Becker-Tomes model in relation to a more mechanical model of intergenerational transmission. As he points out, the prediction of a negative association between grandparent's education and child's education (conditional on parent's education) could also be in line with a "two-state variable mechanical system".
} 
estimations on the full sample and on a sample where the great grandparents were no longer alive at the time of the birth of the child.

\subsection{Empirical test}

Table shows the results from regression of education of a child on the education of parents and grandparents. The first two columns show results for years of schooling and the last two columns show results for the probability of graduating from an academic high-school track as the outcome variable for the child. Columns 1 and 3 show results from OLS-regressions and columns 2 and 4 the IV-results. The lower panel of Table shows the first stage results corresponding to the IV-estimates. To adjust for the positive trend in educational attainment over time, and for other variations across cohorts within generations, all regressions control separately for a quadratic in the birth year of the members of all generations. The reported standard errors (in parentheses) are clustered on families. Standardized estimates are reported in brackets.

Our OLS estimations give statistically significant positive estimate for both parents' and grandparents' education. This is in line with results in Lindahl et al. (2012) where we focus on the descriptive pattern of intergenerational mobility across generations using the same data set as in this paper. Note that the OLS estimates reported in columns 2 and 4 constitute the first-stages in the IV-estimations and are just lagged versions of the model's estimates presented in columns 1 and 3, where we have lagged equation (3) one generation. Finally, we note that the size of these estimates are difficult to compare since the distribution of great grandparents' education is very different from the distribution of education for members in other generations. We therefore also report standardized estimates in brackets. Note that these standardized estimates are much more similar across generations. As we show in section 3, these estimates are not consistent, but nevertheless constitute a reference point for our IV-estimations.

Turning to our IV estimations, we first note that estimates from both first stage regressions are highly significant and the $F$-statistics for education of great-grandparents is 33.4 in column 2 and 47.1 in column 4 . This suggests that we have a strong instrument. Moving to the IV-estimates, we find that they are positive and not significantly different from, and actually very similar to, the corresponding OLS- 
estimates. $^{13}$ Since a 95 percent confidence interval covers a negative value of grandparents' education, we cannot reject the Becker-Tomes prediction of a negative coefficient using IV-regressions. ${ }^{14}$

Note that if we are willing to make some strong assumptions can use this framework to derive an upper bound of $\beta$ by using equation (3), where the coefficient for parents schooling equals $\beta+\lambda$ and for grandparents schooling equals $-\beta \lambda$. From the point estimates of the influence of parents and grandparents reported in Table 2, we get that either $\beta$ or $\lambda$, but not both, is greater than zero. As there is abundant and convincing evidence that genes are positively transmitted across generations, we assume that the endowment transmission coefficient $\lambda$ is greater than zero. This would imply that $\beta$, the causal effect of parent's education on the education of the child, is negative. However, a $95 \%$ confidence interval around our estimated $\beta$ would reject that the causal effect of parental education on the education of the child is larger than 0.078. This back of the envelope calculation suggests an estimate much smaller in magnitude than typical OLSestimates, but more in line with recent estimates of the causal effect of education based on outcomes from compulsory school reforms and twins and adoption data (see Black, Devereux and Salvanes, 2005b, and Holmlund, Lindahl and Plug, 2011). ${ }^{15}$

\footnotetext{
${ }^{13}$ We have also checked for non-linear effects of schooling of ancestors in the OLS and IV regressions, but quadratic terms are never statistically different from zero.

${ }^{14}$ Using the estimates in column 2 of Table $2, \beta+\lambda=0.257$ and $-\beta \lambda=0.064$ we can solve for $\beta$ and $\lambda$. This gives $\beta=-0.155$ and $\lambda=0.412$. These estimates are, however, fairly imprecise and in order to investigate how large a positive value of $\beta$ that we can exclude with reasonable statistical confidence we use the delta method to obtain standard errors for the $\beta$ estimates. Assuming independence of estimates of $\beta$ and $\lambda$, we get that the standard error for the estimate of $\beta$ is 0.116 .

${ }^{15}$ In a companion paper (Lindahl et al., 2012), using the same data set as in this paper, we have an entirely descriptive focus and, instead of testing the Becker Tomes model, estimate the degree of intergenerational mobility across multiple generations. We there find a two-generation model to severely under-predicts intergenerational persistence in educational attainment over three and four generations. At first, the findings in the present paper, of a small causal effect of parent's education on the education of children, might seem at odds with the results in Lindahl et al. (2012). However, as shown in Stuhler (2012), using the simple model in equations (1) and (2), what is shown to be most important for long-run persistence is not the magnitude of $\beta$, the causal effect of parent's education on children's education, but instead the magnitude of $\lambda$, i.e. how strongly ability is transmitted across generations.
} 
Table 2: OLS and IV regressions of children's education on parent's and grandparent's education

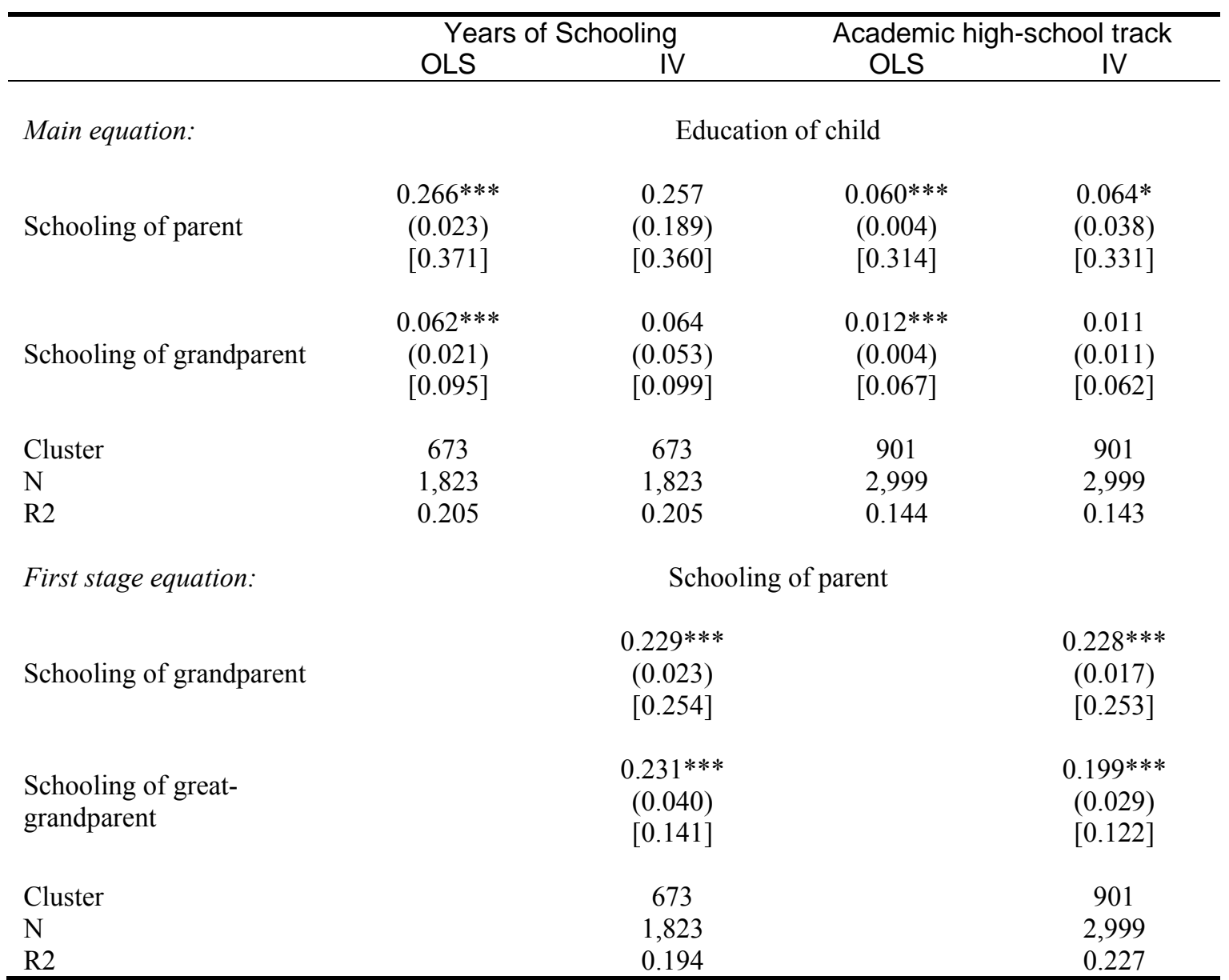

Notes: All regressions control for a quadratic in the birth year of the members of all generations. The reported standard errors (in parentheses) are clustered on families. Standardized estimates are reported in brackets.

The estimates in Table 2 are from regressions on samples of children where the great grandparents could either have died or still be alive at the time of the birth of their great grandchild. This implies that some of these great grandparents may have had a direct influence on the early skill formation of their great grandchildren, suggesting that our exclusion restriction (that the education of the great grandparents has no impact on their great grandchildren's education, conditional on parent's and grandparent's education) would not hold. We therefore also pursue estimations using a sample where the great grandparents died before the birth of their great grandchildren. The samples then become somewhat smaller as we 1) only have death year information for about $91 \%$ of the sample and, 2) because in the sample where we have death year information, about $23 \%$ percent of the children have great grandparents that were still alive at the time of 
their birth. We report these estimates in Table 3, which has a similar structure as Table 2.

Table 3: OLS and IV regressions of children's education on parent's and grandparent's education: including only those children where their great-grandparents died before they were born

\begin{tabular}{|c|c|c|c|c|}
\hline & \multicolumn{2}{|c|}{ Years of Schooling } & \multicolumn{2}{|c|}{ Academic high-school track } \\
\hline & OLS & IV & OLS & IV \\
\hline Main equation: & \multicolumn{4}{|c|}{ Education of child } \\
\hline Schooling of parent & $\begin{array}{c}0.263 * * * \\
(0.026) \\
{[0.367]}\end{array}$ & $\begin{array}{c}0.364 \\
(0.203) \\
{[0.559]}\end{array}$ & $\begin{array}{c}0.059 * * * \\
(0.005) \\
{[0.306]}\end{array}$ & $\begin{array}{c}0.080 * * \\
(0.035) \\
{[0.421]}\end{array}$ \\
\hline Schooling of grandparent & $\begin{array}{c}0.078 * * * \\
(0.024) \\
{[0.120]}\end{array}$ & $\begin{array}{c}0.047 \\
(0.066) \\
{[0.058]}\end{array}$ & $\begin{array}{c}0.012 * * * \\
(0.005) \\
{[0.071]}\end{array}$ & $\begin{array}{c}0.006 \\
(0.011) \\
{[0.035]}\end{array}$ \\
\hline $\begin{array}{l}\text { Cluster } \\
\mathrm{N} \\
\mathrm{R} 2\end{array}$ & $\begin{array}{c}476 \\
1,162 \\
0.205\end{array}$ & $\begin{array}{c}476 \\
1,162 \\
0.192\end{array}$ & $\begin{array}{c}717 \\
2,118 \\
0.144\end{array}$ & $\begin{array}{c}717 \\
2,118 \\
0.135\end{array}$ \\
\hline First stage equation: & \multicolumn{4}{|c|}{ Schooling of parent } \\
\hline Schooling of grandparent & & $\begin{array}{c}0.263 * * * \\
(0.027) \\
{[0.292]}\end{array}$ & & $\begin{array}{c}0.237 * * * \\
(0.020) \\
{[0.263]}\end{array}$ \\
\hline $\begin{array}{l}\text { Schooling of great- } \\
\text { grandparent }\end{array}$ & & $\begin{array}{c}0.258 * * * \\
(0.049) \\
{[0.157]}\end{array}$ & & $\begin{array}{c}0.215 * * * \\
(0.034) \\
{[0.131]}\end{array}$ \\
\hline $\begin{array}{l}\text { Cluster } \\
\mathrm{N} \\
\mathrm{R} 2\end{array}$ & & $\begin{array}{c}476 \\
1,162 \\
0.182 \\
\end{array}$ & & $\begin{array}{c}717 \\
2,118 \\
0.227\end{array}$ \\
\hline
\end{tabular}

Notes: All regressions control for a quadratic in the birth year of the members of all generations. The reported standard errors (in parentheses) are clustered on families. Standardized estimates are reported in brackets.

We first note that the OLS estimations for this subsample of children generate very similar estimates as the full sample. Turning to our IV-estimations, we note somewhat larger estimates for parents' education and somewhat smaller estimates for grandparents' education. However, these estimates are statistically indistinguishable from the estimates reported in Table 2 using the full sample. Again, we cannot reject the Becker-Tomes prediction of a negative coefficient using IV-regressions. 


\section{Conclusions}

We have explored intergenerational transmission of education using data on four generations over the span of a century. We are able to link great-grandparents born at the end of the nineteenth century to great-grandchildren who finished their education in the early twenty-first century. We test the well-known Becker-Tomes model of intergenerational transmission of human capital and use it to estimate the causal effect of parental education on child outcomes, using educational attainments of the first generation as an instrumental variable. We fail to find support for this key prediction of the Becker-Tome model.

As we described in the Introduction of this paper, there are two main economic models for describing intergenerational transmission of human capital: a galtonian model where different endowments are transmitted "mechanically" between generations and the Becker-Tomes model where parents invest in the future return of the human capital of their children. Since our IV estimates suggest that we cannot reject a zero influence of grandparent education on the educational attainment of their grandchildren we are not able to empirically prove the testable implication of a negative influence. Our overall conclusion is that we maintain the model of mechanical transmission of human capital as the best description of the process of intergenerational transmission of human capital. 


\section{References}

Becker, G. S. and N. Tomes (1979), "An Equilibrium Theory of the Distribution of Income and Intergenerational Mobility", Journal of Political Economy 87(6), 115389.

Becker, G. S. and N. Tomes (1986), "Human Capital and the Rise and Fall of Families" Journal of Labor Economics 4(3), S1-39.

Behrman, J. R. and P. Taubman (1985), "Intergenerational Earnings Mobility in the US and a Test of Becker's Intergenerational Endowments Model", Review of Economics and Statistics 67, 144-151.

Björklund, A., M. Lindahl and E. Plug (2006), "The Origins of Intergenerational Associations: Lessons from Swedish Adoption Data", Quarterly Journal of Economics 121(3), 999-1028.

Black S., P. Devereux and K. G. Salvanes, (2005a), "The More the Merrier? The Effect of Family Size and Birth Order on Children's Education", Quarterly Journal of Economics 120(2), 669-700.

Black, S. and P. Devereux (2010), "Recent Developments in Intergenerational Mobility", in O. Ashenfelter and D. Card (eds.), Handbook of Labor Economics, Vol. 4B, Ch. 16, Amsterdam: Elsevier.

Black, S., P. Devereux and K. G. Salvanes (2005b), "Why the Apple Doesn't Fall Far: Understanding Intergenerational Transmission of Human Capital", American Economic Review 95(1), 437-449.

Goldberger, A. (1989) "Economic and Mechanical Models of Intergenerational Transmission", American Economic Review 79(3), 504-513.

Holmlund, H., M. Lindahl and E. Plug (2008), “The Causal Effect of Parents' Schooling on Children's Schooling: A Comparison of Estimation Methods", IZA Discussion Paper 3630.

Holmlund, H., M. Lindahl and E. Plug (2011), "The Causal Effect of Parents' Schooling on Children's Schooling: A Comparison of Estimation Methods", Journal of Economic Literature 49(3), 614-650.

Lefgren, L., M Lindquist, and D. Sims (2011), "Rich Dad, Smart Dad: Decomposing the Intergenerational Transmission of Income," Mimeo, SOFI, Stockholm University, October 2011.

Lindahl, M., M Palme, S Sandgren Massih, and A Sjögren (2012), "Long-term intergenerational persistence of human capital: an empirical analysis of four generations," Mimeo, Uppsala University, December 2012.

Mulligan, C. B. (1997), Parental Priorities and Economic Inequality, Chicago: University of Chicago Press. 
Mulligan, C. B. (1999), "Galton versus the Human Capital Approach to Inheritance," Journal of Political Economy, 107 (S6), S184-S224

Piketty, T. (2000), "Theories of Persistent Inequality and Intergenerational Mobility", Chapter 8 in Handbook of Income Distribution Vol(1), Edited by A.B. Atkinson and F. Bourguignon.

Plug, E. och W. Vijverberg (2003), "Schooling, Family Background, and Adoption: Is it Nature or Is it Nurture", Journal of Political Economy 111(3), 611--41.

Plug, E. and W. Vijverberg (2005), "Does Family Income Matter for Schooling Outcomes? Using Adoptees as a Natural Experiment”, Economic Journal 115(506), 880-907.

Sauder, U. (2006), "Education Transmission across Three Generations - New Evidence from NCDS Data", Mimeo, University of Warwick.

Solon, G. (1999), "Intergenerational Mobility in the Labor Market", in O. Ashenfelter and D. Card (eds.), Handbook of Labor Economics, vol. 3, ch. 29, 1761-1800, Amsterdam: Elsevier.

Stuhler, J (2012), "Mobility Across Multiple Generations: The Iterated Regression Fallacy”, IZA Discussion Paper 7072. 